\title{
INFLUÊNCIA SÓCIOECONÔMICA DA EXISTÊNCIA DOS GRUPOS DE POUPANÇA E CRÉDITO ROTATIVO NO DISTRITO DE MARRACUENE, PROVÍNCIA DE MAPUTO-MOÇAMBIQUE
}

\author{
Nelson Maria Rosário ${ }^{1}$
}

\section{Resumo}

O presente artigo avalia a influência socioeconômica da existência dos grupos de poupança e crédito rotativo no distrito de Marracuene. Para o alcance dos objetivos preconizados no estudo, optou-se pelo uso da abordagem qualitativa e quantitativa, tendo sido inquiridos 30 integrantes dos Grupos de Poupança e Crédito Rotativo existentes no distrito de Marracuene e entrevistados dois técnicos afetos ao Serviço Distrital de Atividades econômicas de Marracuene que assistem os grupos existentes. Dentre vários aspetos positivos que podem se elencar dos Grupos de poupança e crédito rotativo (GPCR), a mais importante é o fato de os grupos de Poupança e Crédito constituírem em verdadeiras escolas de gestão financeira e de promoção das poupanças para as comunidades. Os resultados do estudo mostraram que as famílias inserida nos GPCR melhoraram as suas condições sociais bem como econômicas, são os casos de acesso a saúde, educação, habitação e capital para iniciar novos negócios. Assim sendo, foi possível concluir-se que a existência de Grupos de Poupança e Crédito Rotativo no distrito de Marracuene, tem impactos sociais e econômicos positivos.

Palavras-chave: Influência socioeconômica, Poupança e Crédito Rotativo, e Marracuene.

\section{SOCIOECONOMIC INFLUENCE OF THE EXISTENCE OF SAVINGS AND ROTATING CREDIT GROUPS IN THE MARRACUENE DISTRICT, MAPUTO- MOZAMBIQUE PROVINCE}

\begin{abstract}
This article assesses the socio-economic influence of the existence of savings and revolving credit groups in the district of Marracuene. To achieve the objectives recommended in the study, we opted for the use of the qualitative and quantitative approach, having been interviewed 30 members of the Savings and Revolving Credit Groups in the Marracuene district and interviewed two technicians assigned to the District Service of Economic Activities of Marracuene that assist existing groups. Among several positive aspects that can be listed in the Savings and Revolving Credit Groups (GPCR), the most important is the fact that the Savings and Credit groups are truly schools of financial management and promotion of savings for communities. The results of the study showed that families inserted in the GPCR improved their social as well as economic conditions, such as access to health, education, housing and capital to start new businesses. Therefore, it was possible to conclude

\footnotetext{
${ }^{1}$ Professor da Escola Superior de Negócios e Empreendedorismo de Chibuto (ESNEC/UEM) e Doutorando em Desenvolvimento Rural na Universidade Federal do Rio Grande do Sul. E-mail: nemaro17@gmail.com.
} 
that the existence of Savings and Revolving Credit Groups in the Marracuene district, has positive social and economic impacts.

Key Words: Socioeconomic influence, Savings and Revolving Credit, and Marracuene.

\section{INFLUENCIA SOCIOECONÔMICA DE LA EXISTENCIA DE AHORRO Y GRUPOS DE CRÉDITO GIRATORIO EN EL DISTRITO DE MARRACUENO, PROVINCIA DE MAPUTO-MOZAMBIQUE}

\section{Resumen}

Este artículo evalúa la influencia socioeconômica de la existencia de grupos de ahorro y crédito rotativo en el distrito de Marracuene. Para lograr los objetivos recomendados en el estudio, optamos por el uso del enfoque cualitativo y cuantitativo, habiendo entrevistado a 30 miembros de los grupos de Ahorro y Crédito Rotativo en el distrito de Marracuene y entrevistando a dos técnicos asignados al Servicio de Actividades Econômicas del Distrito de Marracuene que ayudan a grupos existentes. Entre varios aspectos positivos que se pueden enumerar en los Grupos de ahorro y crédito rotativo (GPCR), el más importante es el hecho de que los grupos de ahorro y crédito son verdaderas escuelas de gestión financiera y promoción de ahorro para las comunidades. Los resultados del estudio mostraron que las familias insertadas en el GPCR mejoraron sus condiciones sociales y econômicas, como el acceso a la salud, la educación, la vivienda y el capital para comenzar nuevos negocios. Por lo tanto, fue posible concluir que la existencia de Grupos de Ahorro y Crédito Rotativo en el distrito de Marracuene tiene impactos sociales y económicos positivos.

Palabras claves: Influencia socioeconômica, ahorro y crédito rotativo, y Marracuene.

\section{INTRODUÇÃOO}

Este trabalho aborda a questão dos Grupos de Poupança e Crédito Rotativo (GPCR) existentes no distrito de Marracuene, Província de Maputo, a mesma procura avaliar a influência que esta atividade traz na vida das famílias e consequentemente no desenvolvimento do distrito. É nesse sentido que Carrilho e Teyssier (2011) afirmam que o desenvolvimento ocorre de modo relativamente mais rápido e sustentável nas sociedades com sólidas práticas de poupança. Tal como muitas outras práticas, a poupança também se pode desenvolver, através da educação familiar e dos círculos sociais mais próximos.

De acordo ainda com os mesmos autores, as ASCAS (Grupos de Poupança Acumulativa ou Rotativa), são uma forma organizada de desenvolvimento das tradições de ensino e aprendizagem de boas práticas de gestão dos recursos financeiros na sociedade, 
tendo como embrião os grupos conhecidos como "xitique ${ }^{2}$ " ou outra designação conforme a região de Moçambique. Os grupos de Poupança e Crédito Rotativo tem em várias regiões do nosso país criado efeitos positivos, onde através do acesso ao crédito as famílias conseguem melhorar as suas condições de vida, assegurar a educação dos filhos, ampliação dos seus negócios, entre outras melhorias que se verificam.

Ao estudar os grupos de poupança e crédito rotativo, não pretendemos de forma alguma reduzir ou desvalorizar a relevância existencial de qualquer outra pesquisa que tenha sido feita sobre o tema em estudo, mas sim, pretendemos trazer mais uma alternativa bibliográfica sobre o fenómeno dos GPCR. É neste propósito, que o presente trabalho surge na tentativa de dar mais um contributo ao debate que vem sendo feito sobre os serviços financeiros tendo em conta que essa prática é realizada a nível do país, e que os mesmos grupos movimentam elevadas quantias de dinheiro fora do sistema financeiro formal.

\section{ALGUNS CONCEITOS SOBRE GRUPO DE POUPANÇA E CRÉDITO (GPC)}

Em Moçambique existem vários tipos de ASCAS ou Grupos de Poupança e Crédito Rotativo. Os grupos de poupança e crédito rotativo, surgem para responder as lacunas existentes nos bancos que geralmente são constituídas por políticas rígidas para as comunidades de baixo rendimento. A sua característica é o envolvimento da comunidade e dos seus membros na gestão das estruturas financeiras locais, uma metodologia que permite substituir as garantias formais por garantias morais.

“Os GPC (Grupos de Poupança e Crédito) são um conjunto de pessoas que se reúnem por afinidade, vizinhança ou associativismo em atividades socioeconômicas para realizarem operações de poupança, crédito e pagamento de juros associados ao crédito" (ALLEN \& STAEHLE, 2011.p.12).

Segundo Carrilho \& Teyssier, (2011, p.5), “os grupos de poupança acumulativa ou rotativa são uma forma organizada de desenvolvimento das tradições de ensino e aprendizagem de boas práticas de gestão dos recursos financeiros na nossa sociedade, tendo como embrião os grupos conhecidos como xitique".

\footnotetext{
${ }^{2}$ Xitique é uma palavra Tsonga que significa poupança. É uma das formas de realização de poupanças. O processo inicia normalmente a partir de um grupo de amigos que se juntam, fixam o montante da contribuição de cada membro e a periodicidade dos encontros para prestação de contas e distribuição rotativa da poupança, por cada um deles.
} 
Para Ali \& Ibraimo (2014, p.8), “os GPC são um conjunto de pessoas que geralmente se reúnem por afinidade, vizinhança ou associativismo em atividades socioeconômica para realização de poupanças, que por sua vez são usadas para a concessão de crédito".

De acordo com GPCR (2016, p.7) “os Grupos de Poupança e Crédito Rotativo (PCRs) vulgarmente denominados ASCAS são formas organizativas de promoção do acesso da população de baixa renda aos serviços financeiros, particularmente nas zonas rurais".

As abordagens dos autores acima citados sugerem que existe um comum entendimento na percepção do conceito grupos de poupança e crédito rotativo. Na perspectiva de mostrar a influência socioeconômica da existência dos GPCR, o presente estudo adota o conceito de J.Carrilho \& Teyssier (2011), por ser o que melhor se enquadra e pela simplicidade e clareza apontado para a influência entre o homem e a gestão de recursos financeiros.

\section{Surgimento dos Grupos de Poupança e Crédito Rotativo}

Segundo Carrilho \& Teyssier (2011, p.9), em Moçambique, o modelo de grupos de poupança e crédito começou por ser implementado na altura em que a lei bancária não autorizava a captação de poupanças ao nível associativo, e os primeiros grupos de poupança e crédito trabalhavam na realidade, com empréstimos do projeto promotor (Caixa Comunitária de Crédito e Poupança - projeto CCCP). Esses grupos iniciais estavam organizados ao nível comunitário, numa aldeia e ou nas zonas rurais, e eram concebidas como instituições autónomas legalmente constituídas. Este modelo de "microfinanças descentralizadas" é particularmente bem adaptado para as zonas rurais, de acesso mais difícil ao crédito e de custos de atendimento mais caros que as zonas urbanas.

Autores como Ali \& Ibraimo (2014) afirmam que foi por volta da década 90 que a criação destes grupos teve de entre outros, como objetivo promover o acesso da população de baixa renda e excluída do SFF (sistema financeiro formal), com maior ênfase nas mulheres. A promoção destes grupos já vinha sendo desenvolvida pela CARE na África Oriental e Ocidental, onde o sucesso atingido conduziu à reprodução desta experiência em outros países africanos. 
Desde 1997, a CARE experimentou na província de Nampula, no âmbito do projeto CRESCE, várias metodologias de serviços financeiros à população de baixa renda. Neste contexto, os primeiros grupos de Poupança e Crédito Rotativo foram experimentados a partir de 2000 no distrito de Moma. A avaliação das diferentes alternativas mostrou que os GPCR tinham tido os melhores resultados, e o modelo foi promovido a partir de 2002 num novo projeto chamado "Ophavela". Em 2004, a Ophavela foi institucionalizada como Associação de direito moçambicano dedicada à promoção de PCR (Poupança e Crédito Rotativo), o que faz até agora, com apoios financeiros de diferentes parceiros, (CARRILHO \& TEYSSIER, 2011, p.20).

Contudo os mesmos autores afirmam que o modelo PCR foi rapidamente adotado pelo IDPPE (Instituto de Desenvolvimento da Pesca de Pequena Escala) por ser um potente instrumento de desenvolvimento social e o IDPPE promoveu a criação de grupos nas suas zonas de atuação, diretamente (em Cabo Delgado e Norte de Nampula), ou por via de ONG's locais contratadas para o efeito. Assim, na zona de atuação do projeto "Banco de Sofala" (com financiamento do IFAD), contratou a ADEM, em Sofala, a KULIMA na Zambézia e OPHAVELA em Nampula e, mais recentemente, a KULIMA para o projeto de desenvolvimento da pesca artesanal nas províncias de Gaza e Inhambane (PPAGI - com financiamento da FAO).

A metodologia de Poupança e Crédito Rotativo para Carrilho \& Teyssier, (2011, p.7) tem mostrado a sua maior potencialidade para oferecer serviços financeiros básicos à população mais distante, social e geograficamente, do que outras instituições financeiras, incluindo as IMF/OMF. Hoje, os membros dos GPCR representam uma população quase igual à servida pelas IMF/OMF, localizada nos distritos onde as IMF/OMF, concentradas nas maiores cidades dos pais, não chegam.

Revelou-se um fator fundamental de "educação financeira", permitindo na prática que essa população conheça e entenda conceitos financeiros básicos como poupança, capital, juros, prazo de crédito, obrigação de pagamento do crédito, etc. Assim, essa população está mais preparada para, um dia, aproximar-se das instituições financeiras formais e realizar aí operações bancárias, sofrendo menos os inconvenientes da assimetria da informação entre as partes.

\section{Características e Funcionamento dos Grupos de Poupança e Crédito Rotativo}

"Existe uma notória variabilidade no que respeita ao funcionamento cada GPCR tem suas próprias especificidades em termos de regras para acomodar diferentes ambientes, propósitos ou emergências", (ALI \& IBRAIMO, 2011, p.6). O funcionamento do GPCR é influenciado pela organização que promove a sua criação sendo assim, as características e o 
funcionamento dos GPCR variam em função da metodologia e objetivos de cada operador/promotor.

Em geral, as atividades financeiras dos GPCR são para Ali \& Ibraimo (2014, p.4), realizadas num período que varia de 6 a 12 meses dependendo de cada grupo, denominado por ciclo. O ciclo de poupança e crédito inicia-se no primeiro encontro do grupo e termina no dia da distribuição aos membros dos valores que foram acumulados ao longo do ciclo. Durante o ciclo, os membros dos grupos encontram-se para realizar as suas atividades financeiras de poupança e empréstimo. "Dependendo da metodologia, podem existir nos grupos valores mínimos e máximos de poupança ou somente valores mínimos que são estipulados de acordo com a dinâmica económica das zonas onde estes grupos se localizam e com base na capacidade financeira dos membros. A sua característica é o envolvimento da comunidade e dos seus membros na gestão das estruturas financeiras locais, uma metodologia que permite substituir as garantias formais por garantias morais", (CARRILHO \& TEYSSIER,2011, p.10).

De acordo com GPCR (2016,p.7), os grupos de Poupança e Crédito Rotativo consistem em associações de 15 a 30 membros com o objetivo de prestar serviços financeiros entre si e podem crescer até transformar-se em associações de 300 a 1.000 membros. As poupanças depositadas regularmente junto do grupo em reuniões (semanais, quinzenais ou mensais) são a base para o crédito. Antes do início dos depósitos, os grupos são capacitados pelos provedores de serviços, definem as regras de trabalho e elegem um comité de gestão. Em cada reunião, cada pessoa deposita conforme as suas possibilidades e estes valores variam geralmente de 10 a 500 meticais. O ciclo de poupanças corresponde aos ciclos econômicos da zona e varia entre 8 e 12 meses e é desta forma que os grupos urbanos têm ciclos de trabalho diferentes dos grupos rurais.

Em relação aos empréstimos, Ali \& Ibraimo (2014,p. 6) defendem que estes são de curto prazo (geralmente de um a três meses) e são concedidos apenas aos membros do grupo (não há empréstimos para pessoas que não fazem parte do grupo) mediante o pagamento de uma taxa de juro mensal, que varia entre $5 \%$ a $25 \%$ dependendo da decisão do grupo. De acordo com as normas de funcionamento dos grupos, o reembolso dos empréstimos fora dos prazos definidos são sancionados com o pagamento de uma multa previamente estipulada pelo grupo. 
“Os grupos possuem um sistema de registo de informação das transações financeiras (valores poupados, empréstimos concedidos, juros pagos, fundo social ${ }^{3}$, multas e outras contribuições) feitas em cadernetas/fichas individuais e/ou em cadernos coletivos. A gestão do funcionamento do grupo e o registro das operações são feitos por um comité de gestão eleito pelo grupo. Os valores monetários das poupanças e remanescentes (após empréstimos ou cobranças de juros, fundo social e multas) movimentados no grupo são depositados numa caixa ou cofre com duas ou três chaves, controlado pelo guardião de caixa", (Ali \& IBRAIMO 2014, p144).

Portanto, a atividade financeira destes grupos consiste em mobilizar poupança dos seus membros e, com base nesta poupança, conceder crédito sobre o qual são cobradas taxas de juro, gerando assim rendimentos que são redistribuídos pelos membros do grupo no final de um dado ciclo.

\section{Influência socioeconômica dos grupos de poupança e crédito rotativo em Moçambique}

Para Ali \& Ibraimo (2014, p.20), em Moçambique, há uma crescente abordagem dominante sobre o papel dos grupos de poupança e credito rotativo no desenvolvimento, suportada pelas organizações que promovem ou financiam os GPCR (Grupos de Poupança e Credito Rotativo), de que a criação dos mesmos capacita a população excluída do sistema financeiro e acesso a serviços financeiros básicos, nesta perspectiva espera-se que a literacia financeira conduza a inclusão financeira ao aumento dos ativos para financiar pequenos negócios e a redução da pobreza e inclusão social resultante da interajuda dos fundos socias dos GPCR.

"Um crescente e cada vez mais robusto conjunto de evidências sugerem que a participação nos grupos de poupança contribui para aumentar a poupança, acesso ao crédito, acumulação de ativos, investimento empresarial, consumo, segurança alimentar, capital social e resiliências" (TRINDADE, 2015, p.11).

De acordo com Muchanga (2016), citando o Fundo de Apoio à Reabilitação Económica (FARE), "mais de 12 mil grupos comunitários de Poupança e Crédito Rotativo (PCRs) existentes no país estão a movimentar mais de 360 milhões de meticais".

3 O fundo social é obtido por meio de contribuições de valores iguais pelos membros do GPC e com uma periodicidade regular e não é sujeito a juros. Este fundo é normalmente usado para apoiar os membros do grupo em casos de imprevistos (morte, incêndio, acidentes, doenças entre outros) durante o ciclo (Allen \& Staehle, 2011). 
Dos estudos realizados por Carrilho e Teyssier (2011,p.23) sobre o impacto da PCR (Poupança e Crédito Rotativo), todos apontaram:

Que as poupanças acumuladas até o fim do ciclo tiveram um efeito positivo na vertente económica visto que, contribuíram para a capacidade de investimento dos membros, melhoraram a habitação e de bens domésticos ou produtivos (bicicletas, loiças, telefone, animais de pequeno porte); obtiveram capital inicial para investimento dos seus negócios e em particular nas suas unidades de produção agrícola; aumentaram a capacidade de resistência a crises (doenças, falecimento de familiar); melhoraram a segurança alimentar e a educação dos filhos (CARRILHO E TEYSSIER 2011, p.23).

Além da vertente econômica, a metodologia de PCR contribui da mesma forma no aumento do capital social dos membros. Ou seja, a adesão ao grupo permite reforçar ou criar laços de solidariedade entre os membros, manifestados pela compreensão que existe em caso de dificuldades de um dos membros e no apoio que o grupo procura providenciar, não só através do fundo social mas de outras formas (CARRILHO \& TEYSSIER, 2011,p.23).

A disponibilidade das poupanças, e os investimentos produtivos ou em bens levam ao aumento da capacidade de resistência a crises (doenças, falecimento de familiar), e aumento da segurança alimentar. O "espírito de grupo" é forte, concretizado por atividades sociais conjuntas como canções e danças, "festa" no dia da distribuição dos fundos, (CARRILHO \& TEYSSIER, 2011, p.24).

O financiamento de consumo de bens duráveis é outra utilidade destacada pelos membros dos GPCR. Especificamente, a construção de casas melhoradas, a aquisição de eletrodomésticos, mobiliário, vestuário, dentre outros são as finalidades apontadas como sendo financiadas por meio do acesso a finanças via GPCR.

Para além do mencionado, aponta-se a contribuição para o reforço do papel socioeconômico da mulher. A mulher tem sido vista como sendo mais vulnerável em termos do seu enquadramento socioeconômico. Grande parte dos operadores, como a CARE, no início da promoção de GPCR tinha e continua a ter um enfoque nas mulheres que se encontram em situação economicamente vulnerável com o intuito de possibilitar uma maior participação das mulheres nos GPCR e na comunidade e fortalecer o seu papel de modo a que estas possam ter maiores capacidades de gestão dos seus recursos e de liderança. $O$ foco na inserção de mulheres nos GPCR tem subjacente a ideia de que, por um lado, a participação destas aumenta o seu respeito e autoestima na comunidade. Por outro lado, tendem a aplicar a maior parte dos seus rendimentos nas suas famílias comparativamente aos homens que tendem a investir menos de metade do que auferem (PLAN, BARCLAYS \& CARE, 2013,p.16). 


\section{PROCEDIMENTOS METODOLÓGICOS}

Trata-se de uma pesquisa exploratória e descritiva pois, visa desenvolver e esclarecer ideias sobre os grupos de poupança e crédito rotativo tendo em conta o contexto de Moçambique. A mesma baseou-se numa combinação de abordagens metodológicas qualitativas e quantitativas, devido a natureza da pesquisa e as vantagens que ambos oferecem quando usados em simultâneo.

Estabeleceu-se uma corelação entre a informação bibliográfica e a informação documental contida em artigos, estudos académicos de outros pesquisadores e estudos científicos que procuram entender a temática em estudo. $\mathrm{O}$ inquérito ou questionário foi a principal técnica de coleta de dados.

A mostra deste trabalho foi não probabilística. Em Moçambique existem 5300 GPCR e no distrito de Marracuene existem 24 grupos de Poupança e Crédito Rotativo. Dos 24 grupos existentes, fez-se uma escolha aleatória dos integrantes na qual com as informações obtidas pudessem ser generalizadas para os restantes elementos dos grupos. Assim sendo, foram escolhido 30 integrantes dos grupos existentes para responder ao inquérito. Os integrantes selecionados fazem parte dos grupos registrado nos Serviços Distrital de Atividades Económica (SDAE). Os grupos estudados foram: Lhuvuco Batalão, Ndjombo, Ndjombo I, Ndjombo II, Nfuneca I, Nfuneca II, Lhuvuco André Awade, Nfuneca André Awade, Lirandzo Lava Dzime, Nhuku Wa Varime.

Os dados obtidos com os questionários foram tabulados, mensurados e analisados de forma quantitativa através do uso do pacote estatístico SPSS Excel, e os dados referentes a questões abertas como sugestões e críticas foram analisados de forma qualitativa.

\section{ANÁLISE E DISCUSSÃO DOS RESULTADOS}

\section{Perfil dos integrantes e funcionamento dos Grupos de Poupança e Crédito Rotativo}

Segundo o responsável pela extensão agrária do distrito, existem em Marracuene Vinte e quatro (24) grupos de Poupança e Crédito Rotativo, todos eles formalizados. Destes, dezoito (18) tem na agricultura a atividade principal e seis (6) se dedicam a atividade pesqueira. Segundo ainda o nosso interlocutor, os grupos foram criados com a finalidade de melhorar o nível de vida dos agricultores e pescadores que integram esses grupos tendo em consideração a desigualdades existente em termo de recursos financeiros. 
No que tange ao perfil dos integrantes dos GPCR, foram inquiridos 30 participantes dos GPCR sendo 30\% homens, e 70\% mulheres. Estes dados revelam que os grupos de poupança e crédito existentes no distrito de Marracuene fomentam o empreendedorismo feminino. Portanto, pode-se afirmar que um dos objetivos da criação dos GPCR está sendo alcançado com o grande envolvimento das mulheres, uma vez que a criação das mesmas tinha um enfoque nas mulheres que se encontram em situação economicamente vulnerável, com o intuito de possibilitar uma maior participação delas nos GPCR e na comunidade e fortalecer o seu papel, de modo a que estas possam ter maiores capacidades de gestão dos seus recursos e de liderança.

O foco na inserção de mulheres nos GPCR tem subjacente a ideia de que, por um lado, a participação destas aumenta o seu respeito e autoestima na comunidade e, por outro lado, deriva da ideia de que estas tendem a aplicar a maior parte dos seus rendimentos nas suas famílias, comparativamente aos homens que tendem a investir menos do que a metade do que auferem (PLAN, BARCLAYS \& CARE, 2013, p.12). Isto pode, em parte, justificar o fato de a participação das mulheres ser considerável ao nível dos GPCR. Assim os GPCR têm a tendência de envolver as mulheres que não conseguem se aproximar das outras instituições financeiras, aquela faixa da população totalmente excluída dos serviços financeiros, e majoritariamente associadas a muita pobreza.

No que concerne a faixa etária dos integrantes dos grupos de poupança e crédito rotativo, $46.67 \%$ estão na faixa etária acima de 45 anos, $20 \%$ com idade compreendida entre 35 a 45 anos e $10 \%$ com menos de 25 anos (gráfico 1).

\section{Gráfico1: Distribuição dos inquiridos por faixa etária.}

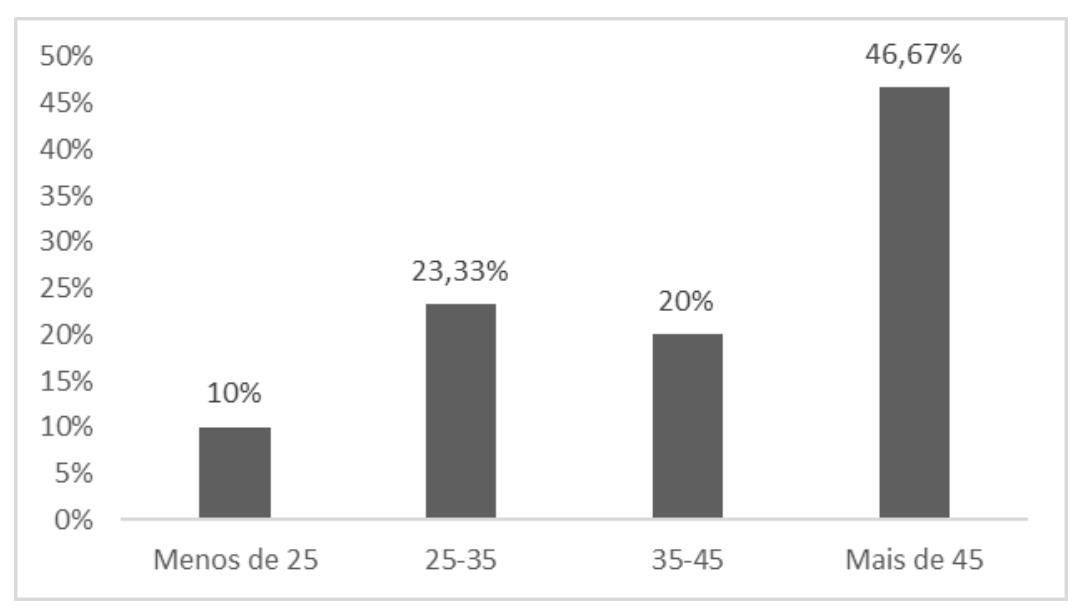

Fonte: Trabalho de campo,2019 
Uma breve análise do gráfico mostra-nos que a acima dos 45 anos o número de indivíduos que participam nos GPCR tende a aumentar, isso deve-se a escolha do tipo de atividade geradora de rendimento praticada pelos participantes.

O nível de escolaridade dos integrantes dos GPCR é baixo. Assim sendo, $66.7 \%$ possuem o nível primário e $13.3 \%$ nunca frequentaram uma instituição de ensino. Portanto, MAE (2014, p.7) sustenta que mais da metade da população é alfabetizada, em grande percentagem para os homens, o distrito de Marracuene, tem taxa de escolarização normal constatando-se que $62.8 \%$ dos seus habitantes, principalmente os residentes no posto administrativo sede frequentam ou já frequentou a escola ainda que até ao nível primário.

O estado civil dos integrantes dos GPCR do distrito revela que 50\% dos inqueridos são solteiros, $43.33 \%$ casados (as) ou a viver em união dos factos e $6.7 \%$ viúvos ou viúvas (Gráfico 2).

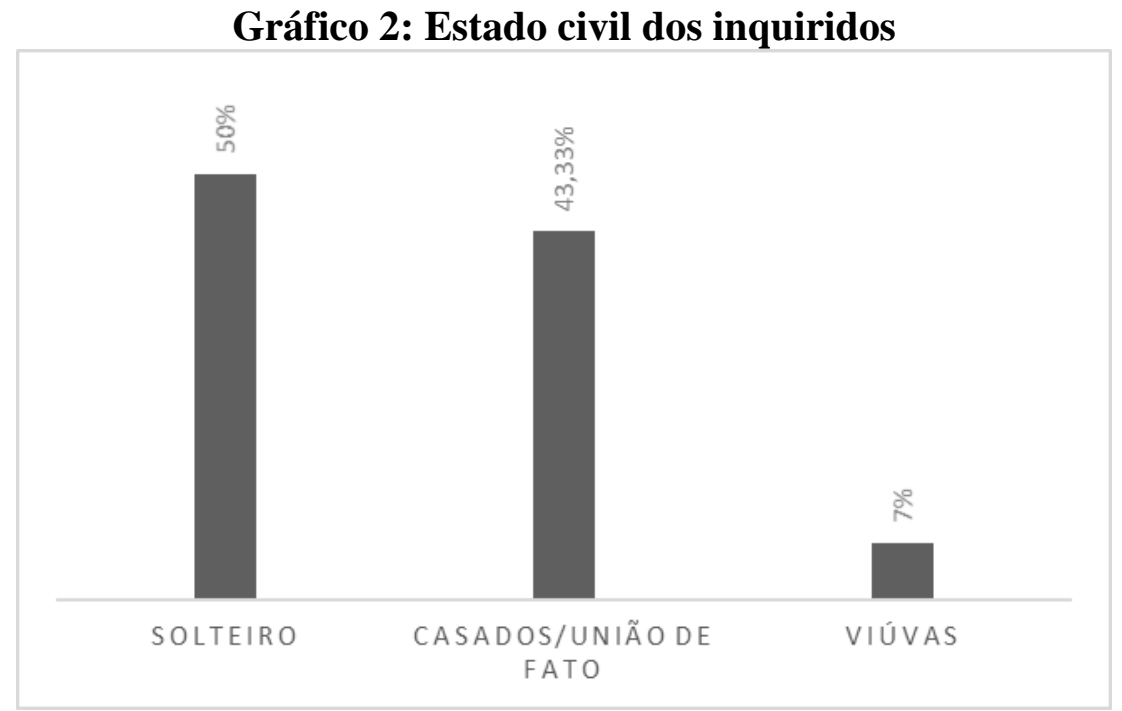

Fonte: Trabalho de campo,2019.

A presença das solteiras (os) como integrantes dos grupos de poupança e crédito mostra que elas/eles são as mais necessitadas (os), são eles (as) que têm dificuldade em arranjar emprego, têm pouco apoio do companheiro (a), por isso, acabam recorrendo aos grupos como um meio de sobrevivência.

A agricultura e a pesca são as principais atividades exercidas pelos integrantes dos GPCR. Assim, 36.67\% afirmaram que desenvolvem a agricultura como atividade geradora de rendimento e $33.33 \%$ tem na pesca a atividade geradora de renda e apenas $30 \%$ disseram exercerem outras atividades que são de pedreiros, carpinteiros, comerciantes e professorado (Tabela 1). 
Tabela 1: Atividade de renda exercida pelos participantes

\begin{tabular}{|c|c|c|}
\hline Atividade exercida & Quantidade & Percentagem (\%) \\
\hline Agricultura & 11 & 36.7 \\
\hline Pesca & 10 & 33.3 \\
\hline Outra & 9 & 30 \\
\hline Total & 30 & 100 \\
\hline
\end{tabular}

Fonte: Trabalho de campo,2019.

Em conversa informal tida com os integrantes dos grupos de poupança e crédito rotativo foram apontados por eles vários aspectos que explica a opção pela atividade agrícola, pelo fato de agricultura ser a atividade predominante em todo o distrito, as condições naturais que o distrito oferece que permite a sua prática. Outros apontaram o fato de eles não terem se formado em uma área específica que pudesse-lhes garantir trabalho formal, e a única saída é optar na agricultura como fonte de emprego e de renda.

Quanto as razões que os fizeram frequentar ou aderir aos grupos de poupança e crédito rotativo, $23.33 \%$ alegam estar próximo da residência, $43.33 \%$ por estar próximo do trabalho, $13.33 \%$ pela facilidade de acolhimento e $20 \%$ por existência no grupo de pessoas conhecidas. Portanto, com esses resultados fica provado que os integrantes dos GPCR se reúnem por afinidade, vizinhança ou associativismo em atividades socioeconômicas para realização de poupanças, que por sua vez são usadas para a concessão de crédito dentro do próprio grupo, através do pagamento de uma determinada taxa de juros.

No que tange a constituição dos grupos, estes são constituídos em média por 25 integrantes. A este propósito, Ali (2014, p.13) "afirma que o número de membros variam em função da metodologia usada e limites estipulados pelo próprio grupo, sendo geralmente de dimensão que permita gerir e manter confiança dentro do grupo. Segundo o animador, quando os grupos têm mais de 30 elemento cria-se um novo grupo, ainda que inicie com poucos elementos".

Sobre a duração dos ciclos, a questão não é uniforme. É neste âmbito que $53.33 \%$ fazem ciclos curtos que vão de 1 a 6 meses, e 46.67\% ciclo de um (1) ano. Algumas mulheres inqueridas contestavam o fato de os ciclos serem de curto prazo, assim como o fato de os juros cobrados serem elevados e como consequências os empréstimos serem de curto prazo o que contribuía para que o seu esforço de pagamento fosse maior.

No que tange a periodicidade dos encontros, $60 \%$ dos integrantes dos GPCR inqueridos afirmaram ter reuniões semanais e os restantes $40 \%$ tem reuniões mensais e quinzenais. Os grupos que optam por reuniões semanais alegam que essas dinamizam mais o 
ciclo e faz da atividade mais interessante, por outro lado encontros semanais abrem espaço para ajuda imediata.

[...] tive minha machamba afetada por uma praga e não tinha dinheiro para poder comprar os produtos necessários para a pulverização; [...] na mesma semana após perceber esse desastre recorri ao crédito que o Xitique concede e consegui a tempo resolver o problema; [...] Já imagina só se as reuniões/encontros fossem mensais, teria perdido a minha produção por falta de dinheiro (integrante do GPCR ligado a Agricultura).

Portanto, como se pode constatar maior parte dos integrantes destes grupos olham para os GPCR como meio para solucionar os seus problemas financeiros que podem emergir no dia-a-dia.

No que tange ao valor mínimo da poupança $93.33 \%$ estão no intervalo de 10 a 200,00mt. A base do grupo está nas poupanças, depositadas regularmente junto do grupo quando se reúnem (semanal, quinzenal ou mensalmente). Segundo os inqueridos em cada reunião, cada pessoa deposita conforme as suas possibilidades mas existem alguns grupos como é o exemplo do grupo Nhuku Wa Varime onde o valor mínimo deve ser de 100,00mt.

Para além do valor acordado para a poupança os grupos ainda tiram um certo valor que é acordado pelos integrantes do grupo designado fundo social, este valor varia em cada grupo, como por exemplo o grupo Lirandzo Lava Dzime estipulou 20,00mt como sendo valor do fundo, o grupo Lhuvuco Batalão estipulou 30,00mt. Constatou-se ainda que há uma diferenciação na finalidade do fundo social, onde alguns grupos alocam os valores deste fundo para situações de emergência e imprevistos dos membros e outros aplicam em despesas de funcionamento do grupo (compra de material, pagamento de facilitadores, entre outros). Constatou-se, igualmente, que aqueles grupos que recorrem ao fundo para situações de emergência não acumulam os valores remanescentes (usando-o para organização de festas de fim de ciclo, para compra de capulanas/ camisetas ou mesmo para a redistribuição equitativa entre os membros) para ciclos subsequentes.

Sobre a taxa aplicada aos empréstimos, todos os grupos foram unanimes ao afirmarem o uso de $10 \%$ da taxa de juro. Portanto, deve-se realçar que vários grupos quando se aproxima o fim do ciclo isto é faltando 3 meses já não concedem empréstimos, apenas os membros com dívidas devem reembolsar os créditos e pagar os juros em dívida. É importante realçar que os empréstimos só são concedidos aos elementos que fazem parte dos grupos.

Uma parte considerável dos integrantes dos GPCR inqueridos afirmaram ter uma relação com os bancos comerciais, contudo muitos dos que afirmaram ter conta bancaria 
poucas vezes usam, das vezes que usam é para o efeito de transferência ou depósitos feitos para familiares distantes, afirmou uma das inqueridas. Por outro lado, os participantes que não dispõem de conta bancaria, a imagem que tem desses serviços, está associada a custos elevados para abertura das contas, cobrança de taxas elevadas no ato dos empréstimos e outras exigências feitas pelos bancos comerciais em saber a finalidade do empréstimo sendo que, para a agricultura que é a principal atividade praticada por eles ser considerada como sendo atividade de risco dai que não são concedidos empréstimos.

\section{A influência Socioeconômica da existência dos GPCR no distrito de Marracuene}

Sobre a importância socioeconômica da existência no distrito dos grupos de poupança e crédito rotativo, os integrantes dos grupos inqueridos são unanimes (96.67\%) em afirmar que a atividade de poupança e crédito rotativo é importante para o desenvolvimento das suas atividades e consequente bem-estar social das famílias das mesmas.

Portanto, a maioria dos participantes dos grupos de poupança e crédito rotativo do distrito de Marracuene tem a consciência da importância desses serviços, uma vez que os mesmos afirmam que com o serviço já conseguem realizar poupanças, acumulam os seus ativos, melhoraram a dieta alimentar e conseguem fazer frente as emergências que surgem.

Ainda foi possível verificar que a atividade permite desenvolver relações sociais de interajuda que possibilitam solucionar emergências e fortificação de laços de afinidade e solidariedade entre os membros. A esse propósito, Carrilho \& Teyssier (2011, p.17) afirmam que "além da vertente económica e social, os grupos de poupanças e crédito rotativo contribui da mesma forma no aumento do capital social dos membros". Ou seja, a adesão ao grupo permite reforçar ou criar laços de solidariedade entre os membros, manifestados pela compreensão que existe em caso de dificuldades de um dos membros e no apoio que o grupo procura providenciar, não só através do fundo social mas de outras formas.

Os inqueridos acrescentaram ainda que o espírito de interajuda que se desenvolve no seio dos grupos, permite a existência de apoio a estes muito acima da dimensão social. Ou seja, verificou-se que ocorrem contribuições eventuais fora do GPCR (entre os membros que têm uma certa afinidade) para casos de falecimento, imprevistos (assaltos e/ou destruição de residência, compra de material escolar dos filhos etc). Assim sendo, há que reconhecer o papel que o espírito de interajuda representa no desenvolvimento das relações sociais e na vida dos membros do grupo, uma vez que estas relações se fortalecem na oportunidade que os membros têm de partilhar diferentes problemas sociais que os afetam. 
Atendendo que um dos impactos da existência ou funcionamento dos grupos de poupança e crédito rotativo no distrito é a poupança e obtenção de renda, assim sendo, mais que a metade $(67 \%)$ dos integrantes inqueridos afirmaram que os fatores que influenciam na escolha da aplicação dos retornos da participação em atividade de poupança e crédito dependem das necessidades a suprir, como são os casos de matrícula escolar, compra de uniforme e material escolar, alimentação, entre outras necessidades (Gráfico 3).

\section{Gráfico 3: Factores que influenciam a escolha da aplicação dos retornos obtidos da participação em grupos de poupança e crédito rotativo.}

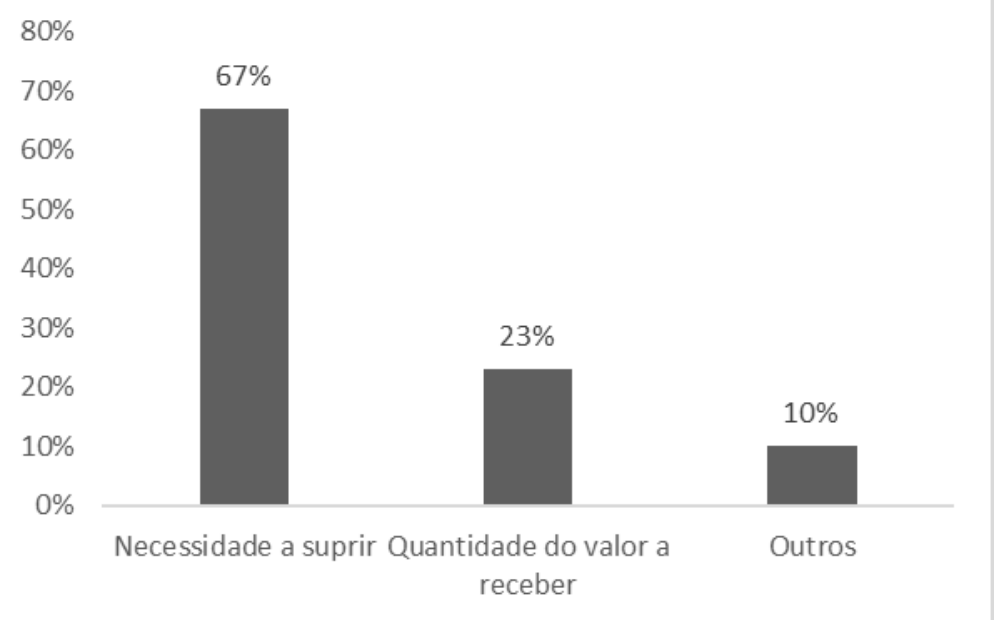

Fonte: Trabalho de campo,2019

A escolha da aplicação dos fundos obtidos (retorno) nos GPCR deve-se em grande parte, segundo os inqueridos, das necessidades que tem a satisfazer, isto é, o final do ciclo as vezes coincide em período que as dificuldades são maiores dentro de casa segundo afirmou uma das participantes do grupo de poupança e crédito rotativo:

[...] Tem vezes que o valor a receber no final do ciclo não cobre os planos traçados [...] as vezes o valor aparece enquanto papa lá em casa não tem dinheiro para compra de material escolar, uniformes, cadernos até mesmo para fazer matricula para as crianças [...] dai que esse dinheiro das poupanças ajuda a suprir essa necessidade (palavras de uma integrante inquerida)

A fala acima vem mostrar que a maioria dos integrantes dos vários grupos de poupança e crédito rotativo existentes no distrito estão satisfeitos com a atividade que exercem. A razão dessa satisfação deve-se ao fato da existência dos GPCR veio minimizar o crónico problema de acesso ao financiamento para o desenvolvimento das suas atividades, uma vez que é difícil obter financiamento a partir das instituições bancarias comerciais existentes no distrito. É nesse sentido, que a satisfação dos beneficiários constitui um 
indicador importante da relevância da existência destes grupos. Outra razão da satisfação prende-se com a transparência que existe no seio dos grupos em termo de funcionamento dos mesmos, principalmente no que diz respeito aos quizitos poupança, crédito, e distribuição do valor no final do ciclo.

Em relação as mudanças ocorridas depois de passarem a fazer parte os GPCR, $80 \%$ dos inqueridos afirmaram houve mudanças consideráveis nas suas vidas (Tabela 2).

Tabela 2: Mudanças verificadas pelos participantes após integrados aos GPCR

\begin{tabular}{|l|c|c|}
\hline Mudanças verificadas & Quantidade & Percentagem (\%) \\
\hline Na habitação & 16 & $20 \%$ \\
\hline Serviços de Saúde e educação & 14 & $17.5 \%$ \\
\hline Agua Potável & 11 & $13.75 \%$ \\
\hline Internet e telefonia Móvel & 6 & $7.5 \%$ \\
\hline Alimentação melhorada & 8 & $10 \%$ \\
\hline Energia elétrica & 9 & $11.25 \%$ \\
\hline Sem mudanças & 6 & $20 \%$ \\
\hline Total & - & $\mathbf{1 0 0 \%}$ \\
\hline
\end{tabular}

Fonte: Trabalho de campo,2019

Dos resultados do trabalho de campo e da observação feita pelos autores, constatou-se que grande parte dos membros entrevistados usam parte dos rendimentos (empréstimos e/ou rendimentos recebidos no final do ciclo) para financiar as despesas de consumo, nomeadamente: alimentação, saúde e educação (matrículas, uniforme, material escolar, etc.), atividade agrícola, aquisição de bens duráveis e semi-duráveis (terreno, instalação de energia elétrica, água, construção e melhoria da habitação, mobiliário, eletrodomésticos, utensílios domésticos) e outras despesas de consumo inesperadas e também usam parte dos recursos para desenvolver a atividade comercial.

Para o técnico agropecuário (assistente dos GPCR), desde que os grupos de poupança e crédito rotativo passaram a atuar no distrito, assistiu-se a melhora no nível de vida dos integrantes, aumentaram os índices de produção e produtividade dos alimentos produzidos nas associações constituídas por esses integrantes. O nosso interlocutor apontou os setores da agricultura, pesca e habitação como os que mais se destacaram com a criação dos GPC. 
Perante as conversas formais e informais tidas com os integrantes dos grupos de poupanca e crédito rotativo do distrito de Marracuene, bem como com os tecnicos afetos ao SDAE que assistem os grupos e pela observação que os autores foram fazendo no seu dia a dia na fase da pesquisa de campo, são apresentados de seguida as vantagens e desvantagens da existencia dos GPCR:

a) Vantagens: (1) Os membros dos grupos podem filiar-se noutras organizações de poupança e crédito, permitindo-lhes fazer parte de outro grupos de poupança a nível familiar ou amigável, dependendo do seu nível de rendimento; (2) Permite acumulação de capital e concessão de crédito sem recorrer as instituições financeiras, deste modo, reduzindo-se o tempo de espera para aquisição de bens e serviços que necessitam de uma soma avultada de valores para o seu consumo; (3) Cria-se uma oportunidade de expansão de fonte de recursos financeiros, para além de aumentar a confiança mútua, fortalecimento das relações sociais, capacidades organizacionais e de liderança na comunidade; (4) $\mathrm{O}$ sistema de controlo interno e contabilização é simples e transparente. Encoraja aos membros a desembolsarem o capital e juro no fim de período estabelecido; (5) Através do capital acumulado, no final do ciclo eleva-se o nível de rendimento familiar, promove-se o custume de poupança, emprendedorismo, expansão do negócio, aquisição de insumos da agricultura e de pesca, melhoria na conservação do pescado, da habitação, de saúde e da dieta alimentar;

b) Desvantagens: (1) As desvantagens deste sistema consistem no impedimento de aplicações de longo prazo, visto que, o período de reembolso do capital é estremamente curto; (2) Quando distribuidas as poupanças no fim do ciclo, recomeçase outro ciclo com poupança nula. Para grupos com menor capacidade de poupança o montante de crédito concedido tem sido reduzido (escassez de liquidez) em relação ao solicitado e gera-se juros somente em caso de concessão de crédito.

\section{CONSIDERAÇÕES FINAIS}

A influência sócioeconômica da existência dos Grupos de Poupança e Crédito Rotativo no distrito de Marracuene, província de Maputo, constatou-se que os Grupos de Poupança e Crédito Rotativo ou ASCAS são uma forma dinâmica usada pelas comunidades excluídas do sistema financeiro formal para ter acesso ao crédito. Esses serviços têm certamente sido alternativa importante para fazer face a deficiência na inclusão financeira em 
Moçambique. Os GPCR têm em parte a capacidade de coesão social, na medida em que, para além das contribuições feitas durante os encontros dos grupos, os membros aproveitam os encontros para o convívio, troca de experiências e vivências, apoio material e moral dos integrantes em casos de enfermidades, mortes e calamidades, estas atividades assentam-se na confiança mutua entre os membros

Os resultados da pesquisa mostraram também que com a integração da população nas atividades dos grupos de poupança e crédito rotativo melhoraram significativamente as condições de vida dos mesmos. No que concerne à expansão de negócios os GPCR são apontados como fonte de financiamento para a expansão do setor comercial local ou seja os membros dos GPCR com acesso a crédito encontram oportunidade para levar avante as suas atividades económicas, caso contrário, teriam que ser abortadas por falta de financiamento.

Por fim, e tendo como base o contexto moçambicano onde o problema da carência de instituições financeiras formais é visível e com base nos resultados que a pesquisa trouxe, pode-se concluir que os grupos de poupança e crédito rotativo são fundamentais para o desenvolvimento socioeconômico, pois a sua ausência dificulta ainda mais o processo de crescimento e consequentemente desenvolvimento do distrito de Marracuene.

\section{REFERÊNCIAS}

Allen, H. \& Staehle, M. Associações Comunitárias de Poupança e Empréstimo. Guião de Formação do Agente Comunitário. Maputo, Moçambique. VSL Associates, 2011.

ALI, Rosimina, et.al. " Grupos de Poupança e Crédito Rurais como Opção para inclusão financeira: uma análise crítica", In: BRITO, Luís de, CASTEL-BRANCO, Carlos Nuno, CHICHAVA, Sérgio (Orgs). Desafios para Moçambique 2014. Maputo: IESE, 2014. P.137162.

ATHMER, G. Manual de Boas Práticas de Grupos de Poupança. Maputo: Fundo de Apoio à Reabilitação da Economia (FARE). Programa de Apoio as Finanças Rurais (PAFR), 2013.

CARRILHO, J., TEYSSIER, S. Grupos de Poupança e Crédito em Moçambique, 10 anos Depois: realizações, desafios e perspectivas. Maputo: FARE-PAFR, 2011.

GPCR. "Grupos de Poupança e Crédito em Moçambique". Boas práticas. MITADER, p.1-7, Junho de 2016. Disponível em Grupos de poupanca e credito Rotativo em Mocambique. Disponível em http://www.ruralmoc.gov.mz/attachments/article/27/GruposdePoupancaeCreditoRotativoem Mocambique.pdf. Acessado em 20. 12.2019.

MAE. Perfil do Distrito de Marracuene, Província de Maputo. Maputo: Direção Nacional de Administração Local (DNAL), 2014 
MUCHANGA, Idnórcio. Poupança e Crédito Rotativo: poupança comunitária gera milhões de meticais. Jornal Domingos, Maputo, 24 de Dezembro de 2016. Economia, 8651.

PLAN, BARCLAYS \& CARE. "Banking on Change: Breaking the Barriers to Financial Inclusion". Banking on change. P.1-28. London, Janeiro 2013.

SILVA, Teresa Cruz e "As Redes de Solidariedade como Intervenientes na Resolução de Litígios: O Caso da Mafalala". In: Santos e Trindade (orgs) Conflito e Transformação Social: Uma Paisagem das Justiças em Moçambique, Edições Afrontamento, Porto, 2003 Cap. 21, pp. 427-450.

TRINDADE, Catarina Cortesão Casimiro Nascimento. Xitiki é compromisso: os sentidos de uma prática de sociabilidade na cidade de Maputo, Moçambique. 2015. Dissertação (Mestre em Antropologia social) - Programa de Pós-Graduação em Antropologia Social do Instituto de Filosofia e Ciências Humanas. Universidade estadual de Campinas (UNICAMP), Campinas-SP, Brasil.

Recebido em Fevereiro de 2020

Aceito em Maio de 2020

Publicado em Julho de 2020 